This item was submitted to Loughborough's Research Repository by the author.

Items in Figshare are protected by copyright, with all rights reserved, unless otherwise indicated.

\title{
A tool to compare all patient handling interventions
}

PLEASE CITE THE PUBLISHED VERSION

http://www.ahfe2010.org/

PUBLISHER

AHFE 2010

VERSION

VoR (Version of Record)

LICENCE

CC BY-NC-ND 4.0

REPOSITORY RECORD

Fray, Mike, and Sue Hignett. 2019. "A Tool to Compare All Patient Handling Interventions". figshare. https://hdl.handle.net/2134/7464. 
This item was submitted to Loughborough's Institutional Repository (https://dspace.lboro.ac.uk/) by the author and is made available under the following Creative Commons Licence conditions.

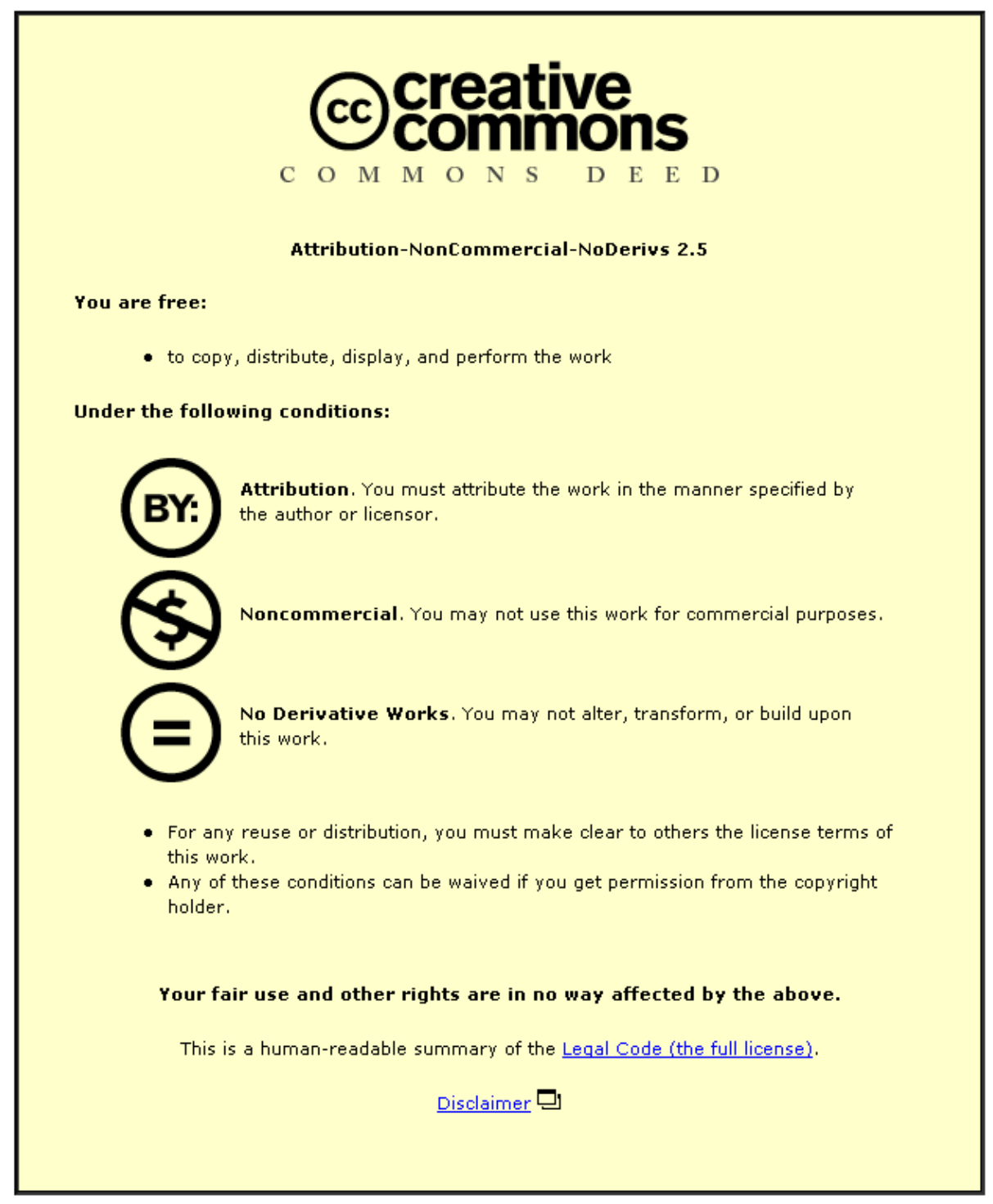

For the full text of this licence, please go to: http://creativecommons.org/licenses/by-nc-nd/2.5/ 
Proceedings of the 1st International Conference on Human Factors and Ergonomics in Healthcare, $3^{\text {rd }}$ International Conference on Applied Human Factors and Ergonomics 17-20 July 2010, Miami, USA

\title{
A Tool to Compare All Patient $\mathrm{H}$ andling Interventions
}

\author{
Mike Fray, Sue Hignett \\ Healthcare Ergonomics and Patient Safety U nit \\ Loughborough University, UK
}

\begin{abstract}
Patient handling intervention strategies are many and varied. The focus of interventions has primarily been on the health, safety and welfare of care givers. Data from $4 \mathrm{EU}$ focus groups and 2 world-wide expert panels were used to evaluate whether other types of outcomes were perceived as having relative importance. Qualitative and quantitative analysis showed that organisational and patient outcomes were also highly rated by the participants. The data showed 12 outcomes as being of the highest priority with good agreement between the $4 \mathrm{EU}$ sources (K endall's Concordance significant at 0.005 ). In parallel, a systematic analysis of patient handling intervention literature was considered to evaluate the qualities of each study. Using the 12 most important outcomes from the initial study and the most appropriate and accessible measurement tools from the literature analysis, the Intervention Evaluation Tool (IET) is proposed. The IET is a single set of measurements that can be used for evaluating all organisational and individual patient handling interventions. The IET has been trialled at 2 sites in 4 EU countries.
\end{abstract}

Keywords: Patient handling, risk management, safety performance, interventions, heal thcare workers, M SD. 


\section{INTRODUCTION}

Patient handling is a known cause of musculoskeletal risk for healthcare staff. A range of ergonomic and other approaches have been used to reduce the effects of these tasks, e.g. risk assessment and management, training, equipment provision, culture change. Comparing the effectiveness of these interventions has been difficult due to the different outcome measures used to evaluate success. Fray and Hignett (2006) found that published patient handling studies used staff outcomes in $77 \%$ and represented patient outcomes in less than $8 \%$ of the investigations. Recent systematic reviews have concentrated on the specific measures of musculoskel etal disorders (M SD) in healthcare staff using the highest level of scientific data (B os et al, 2006, A mick et al., 2006, M artimo et al., 2008) and deduce there is little high quality evidence available and little proven benefit on the rate of MSDs. In comparison Hignett et al (2003) used an inclusive methodology and a quality assessment system to allow a wider range of information to be accessed and included.

The literature does include many different methods for measuring outcomes from patient handling interventions. At present it is very difficult to conduct a meaningful comparison between different styles of interventions or different methods of measuring outcomes. This paper will discuss the relative values of the wider range of outcome measures used to evaluate patient handling interventions and describe the development of an 'inclusive' evaluation tool. If a wide application evaluation tool can be developed then it would prove useful to report successful patient handling interventions and guide organisations to a more directed and streamlined approach of future investment to improve their services.

Experts and practitioners from four European Union (EU) countries participated to add to the content validity and strengthen the evaluation tool for the use across all members of the European Panel of Patient Handling Ergonomics group (EPPHE).

The overall aim of this study is to devel op an intervention evaluation tool (IET) that allows the comparison of different types of interventions on a single score system using a range of outcomes. The three stages of this process are a) identify which outcomes are preferred by patient handling practitioners, b) develop a tool that measures all the preferred outcomes in a single calculation, c) use the tool in 4 EU locations. This study is part of a longer term research partnership investigating patient handling interventions sponsored by Arjo-Huntleigh ab and the EPPHE group.

\section{METHODS}

\section{DEVELOPMENT OF THE INTERVENTION EVALUATION TOOL (IET)}

The first aim, to create identify the most important outcomes was achieved using focus groups across $4 \mathrm{EU}$ countries. The 4 countries included in the study were selected using the following criteria: 
- A bility to access a range of suitable participants.

- Support delivered by a key facilitator to recruit and organise the focus group.

- A chieve a geographical and demographic spread across the EU.

- A mix of levels within the actions taken to implement/answer the EC directive on manual handling in healthcare (Hignett et al, 2007).

The countries selected for the focus groups were UK, Finland, Italy and Portugal.

The structure for the focus group was based on a model by Higgins (1994), known as the 'Nominal Group Technique'. This allows participants to individually record their own thoughts based on a question set. The method was tested at 2 UK and 2 international pilot sessions. Recruitment for the focus group facilitators took place through the EPPHE group network. Several key stages were used to improve the between-groups validity. A dvice was circulated to the focus group facilitators. The following items were included in the guidance:

- The documentation was translated into Finnish / Italian / Portuguese (in the UK ) and sent to the facilitator to checking for translation and content errors.

- Standards for recruiting participants for the group.

- Guidance for the focus group room, facilities and timetable.

As it was essential to standardise the translation and cross checking of feedback from the focus groups, the following process was used:

- A translator was supplied to translate the participant feedback information

- A whispering interpreter was provided to report on the group in real time.

- The discussion groups were transcribed in Finnish / Italian / Portuguese. The transcriptions were translated into English.

- The whispering interpreter was taped and transcribed in English

- The transcriptions from the discussion groups (Finnish / Italian / Portuguese) and whispering interpreter (English) were compared for differences.

Specific instructions were developed to assist the EU facilitators. The EU facilitators all participated in the international pilot studies to learn the process and format. The Principal Investigator (MF) was present at all the EU groups to assist with the standardisation of the process and with the development of the discussion group check list of topics for discussion in collaboration with the EU facilitator and the interpreter. Each focus group was centred around a scenario describing a patient care centre. The participants were invited to give advice to the centre and they were asked which outcomes would they like to measure.

The relative importance of the outcomes was considered within each of the individual and homogenous groups. The following simple analytical style was used:

a) The initial recordings of the preferred outcomes were scored on the content.

b) A computerised qualitative analysis package (NV ivo) was used to identify themes and content from the focus group discussion. This will be reported in a future paper. 
c) The ranked priority lists created by the participants at the close of the focus group interview were scored and ranked on a 5 point scale.

Corrections were made for unequal group sizes before comparisons were made between groups. The ranking scores were added to give a group preference list. All group lists were compared to check for similarities and differences. All the groups were accumulated to give an overall list of the preferred outcomes.

\section{LITERATURE ANALYSIS}

To achieve the second aim of selecting methods for measuring each of the preferred outcomes a detailed analysis of published patient handling studies was completed. Studies were collected using the search strategy used for Hignett et al. (2003) was extended to December 2008. 752 additional papers were assessed against the inclusion criteria and 328 included in the analysis. Each paper was analysed by two independent researchers and the following data were recorded:

- Design of the study

- Characteristics of the intervention

- Quality Rating (QR; Downs and Black, 1998)

- Level of outcome measure (Robson, 2007)

- Ranking of outcome (12 factors from EU study)

- Practitioner rating (from Hignett et al, 2003)

The full comparative data found in this analysis will be presented in a future paper.

\section{EU TRIAL}

Two pilot trials were conducted to assist with the devel opment of the tool. The tool was evaluated in two ward areas in $4 \mathrm{EU}$ countries. The full tool was independently translated and checked by the EU facilitators prior to distribution. EU facilitators collected the data on each site. The primary researcher (M F) was present to observe and record the process. An expert review panel (EPPHE) was conducted after the EU trials to discuss the tool and the methods used.

\section{RESULTS}

Four EU focus groups and 2 worldwide expert panels were completed ( $n=44,9$ countries were represented).

\section{DEVELOPMENT OF THE INTERVENTION EVALUATION TOOL (IET)}

The results from the focus groups and the individual scores were analysed for content and theme (table 1). 210 outcome qualities were recorded in the focus group discussions. The outcome qualities were grouped and compared to give a complex 
definition for each theme. The translated material was returned to the Finnish / Italian / Portuguese focus group facilitator to check for errors in language and translation. The three sets of qualitative and quantitative scores were combined to identify the most highly valued outcomes. The 12 most highly rated outcomes were worthy of further inclusion.

Table 1. N umber of different recorded outcomes

\begin{tabular}{|c|c|c|}
\hline Beneficiary & $\begin{array}{l}\text { Outcomes } \\
\text { included }\end{array}$ & $\begin{array}{c}\text { Outcomes } \\
\text { included in } \\
\text { rankings }\end{array}$ \\
\hline Organisational & 65 & 13 \\
\hline Staff & 57 & 14 \\
\hline Patient & 40 & 7 \\
\hline Task & 30 & 3 \\
\hline Others & 18 & 1 \\
\hline Totals & 210 & 38 \\
\hline
\end{tabular}

The ranked scores recorded at the end of the focus groups were then combined against the thematic definitions to give the ranked list for each country and in total (table 2). Themes that scored less than 5 in any countries combined scores were removed. The same 12 outcomes were seen as most important in each of the 4 countries.

Table 2. Ranked themes for individual and combined EU countries

\begin{tabular}{|c|c|c|c|c|c|c|}
\hline & O utcome theme & $\frac{\lambda}{10}$ & $\frac{8}{8}$ & $\begin{array}{l}\frac{8}{10} \\
\frac{10}{2}\end{array}$ & 亭 & $\begin{array}{l}3 \\
8 \\
1\end{array}$ \\
\hline ร & $\begin{array}{l}\text { A ccident numbers } \\
\text { A bsence or staff health } \\
\text { Financial } \\
\text { Safety Culture }\end{array}$ & $\begin{array}{l}8 \\
3 \\
12 \\
2\end{array}$ & $\begin{array}{l}3 \\
8 \\
12 \\
1\end{array}$ & $\begin{array}{l}11 \\
2 \\
7 \\
1\end{array}$ & $\begin{array}{l}6 \\
4 \\
10 \\
2\end{array}$ & $\begin{array}{c}6 \\
4 \\
12 \\
1\end{array}$ \\
\hline 感 & $\begin{array}{l}\text { M S health } \\
\text { M SD Exposure measures } \\
\text { Competence, compliance } \\
\text { Psychological well-being }\end{array}$ & $\begin{array}{l}1 \\
12 \\
4 \\
10\end{array}$ & $\begin{array}{l}5 \\
9 \\
2 \\
7\end{array}$ & $\begin{array}{l}8 \\
5 \\
4 \\
9\end{array}$ & $\begin{array}{l}1 \\
12 \\
6 \\
4\end{array}$ & $\begin{array}{c}2 \\
10 \\
3 \\
7\end{array}$ \\
\hline $\begin{array}{l}5 \\
0 \\
0\end{array}$ & $\begin{array}{l}\text { Patient injuries } \\
\text { Patient perception } \\
\text { Patient condition } \\
\text { Quality of care }\end{array}$ & $\begin{array}{l}8 \\
8 \\
6 \\
5\end{array}$ & $\begin{array}{l}12 \\
10 \\
7 \\
4\end{array}$ & $\begin{array}{l}11 \\
11 \\
6 \\
3\end{array}$ & $\begin{array}{l}9 \\
8 \\
11 \\
7\end{array}$ & $\begin{array}{c}11 \\
9 \\
8 \\
5\end{array}$ \\
\hline
\end{tabular}




\section{Statistical Analysis}

There is similarity between the $4 \mathrm{EU}$ sets of rankings as the same highly ranked outcomes (safety culture, compliance and MSD measures) are seen in all countries, as are the lower ranked outcomes of finance and patient related measures. It was therefore more appropriate to conduct an analysis for association rather than difference. Kendall's M easure of Concordance was performed using the correction factor for tied ranks and $W=27.66(N=12, d f 11, k=4)$ is significant at the 0.005 level and indicates close agreement between the four EU groups.

The literature analysis examined all the methods used to measure outcomes in the included studies $(n=343$ ). All papers with a QR of $>50 \%$ were included. Table 3 shows the number of methods used for each outcome.

Table 3. Number of methods used to measure outcomes.

\begin{tabular}{lc}
\hline Preferred outcome & $\begin{array}{c}\text { No. methods } \\
\text { included }\end{array}$ \\
\hline 1 Safety Culture & 5 \\
2 M S Health & 45 \\
3 Competence Compliance & 21 \\
4 A bsence or staff health & 19 \\
5 Quality of care & 1 \\
6 A ccident numbers & 2 \\
7 Psychological well being & 8 \\
8 Patient condition & 1 \\
9 Patient perception & 26 \\
10 M SD exposure measures & 170 \\
11 Patient injuries & 0 \\
12 Financial & 10 \\
\hline
\end{tabular}

The outcome measurement methods were assessed using the following inclusion criteria:

- Level of academic quality of the study (QR rating $>50 \%$ ).

- Evidence of peer reviewed validation studies for the method.

- Previously used to score a peer reviewed intervention trial.

- Most frequently used measurement devices.

- Complexity of the data collection in healthcare. The IET incorporated the 12 most preferred outcomes (Table 2) and the most suitable method for measuring each of those outcomes (above). Some of the methods chosen (Table 4) were closely related to known peer reviewed tools and studies $(1,2,3,4,7,9)$. But others required careful consideration of a range of tools $(5,6,10,12)$. The patient outcomes were poorly represented in the literature review and needed new methods of measurement to be devised. 
Table 4. The measure and sources of the IET

\begin{tabular}{|l|l|l|}
\hline \multicolumn{1}{|c|}{ Preferred outcome } & \multicolumn{1}{|c|}{ M ethod for collection } & \multicolumn{1}{|c|}{ Source paper } \\
\hline 1 Safety Culture & $\begin{array}{l}\text { Organisational audit of safety systems } \\
\text { (PHOQS) }\end{array}$ & Hignett (2005) \\
\hline 2 M S health & $\begin{array}{l}\text { M SD level in staff (N ordic } \\
\text { Questionnaire) }\end{array}$ & Dickinson(1992) \\
\hline $\begin{array}{l}\text { 3 Competence/ } \\
\text { Compliance }\end{array}$ & Observational checklist (DiN 0) & Johnsson (2004) \\
\hline $\begin{array}{l}\text { 4 A bsence or staff } \\
\text { health }\end{array}$ & $\begin{array}{l}\text { Standard absence per work population } \\
\text { (OSHA) }\end{array}$ & Charney (1997) \\
\hline 5 Quality of care & $\begin{array}{l}\text { Ward and patient survey to evaluate } \\
\text { care quality }\end{array}$ & Nelson (2008) \\
\hline 6 A ccident numbers & $\begin{array}{l}\text { A ccident numbers and non-reporting } \\
\text { ratios }\end{array}$ & M enckel 1997) \\
\hline $\begin{array}{l}\text { 7 Psychological well } \\
\text { being }\end{array}$ & $\begin{array}{l}\text { 3 part worker for satisfaction and well } \\
\text { being (Bigos) }\end{array}$ & Evanoff (1999) \\
\hline 8 Patient condition & $\begin{array}{l}\text { Patient survey to evaluate clinical } \\
\text { needs }\end{array}$ & Nelson (2008) \\
\hline 9 Patient perception & Survey for comfort, security, fear etc & K jellberg (2004) \\
\hline $\begin{array}{l}\text { 10 M SD exposure } \\
\text { measures }\end{array}$ & $\begin{array}{l}\text { Workload based on patient handling } \\
\text { tasks }\end{array}$ & K nibbe (1999) \\
\hline 11 Patient injuries & $\begin{array}{l}\text { M easure for detrimental effects of } \\
\text { poor handling }\end{array}$ & No source \\
\hline 12 Financial & Calculation of costs versus investment & Chokar (2005) \\
\hline
\end{tabular}

\section{EU TRIALS}

Two wards were selected by the local facilitators to allow the IET to be used to assess the performance of the patient handling management systems. It was not possible to use the IET as a pre-post intervention assessment. The range of scores in each section was clarified with the results from the trial to give best differentiation across the sample. Table 5 shows the percentage scores in each section and the total score for the IET (\%). During the trial some data were not available and the appropriate maximum or minimum score was inserted (italics). The cost benefit analysis was not conducted in this trial but no ward area had access to the costs of sickness absence.

The IET scores differentiated between performance levels, UK 2 had one staff on reduced capacity for 12 months, safety culture scores had weakness for all countries, Portugal scored poorly for compliance and M SD exposure due to poor equipment provision and high risk tasks. The emergency medicine ward in Italy scored the highest overall score, which matched with the EU facilitator's assessment of the ward. Low injury rates and low levels of physical handling reduced risks and improved the IET. 
Table 5 EU trials - \% scores for each IET section and total IET

\begin{tabular}{lcccccccc}
\hline & UK & UK & Po & Po & Fi 1 & Fi & It 1 & It 2 \\
& $\mathbf{1}$ & $\mathbf{2}$ & $\mathbf{1}$ & $\mathbf{2}$ & & $\mathbf{2}$ & & \\
\hline Safety Culture & $\mathbf{5 5 . 6}$ & $\mathbf{4 6 . 7}$ & $\mathbf{1 3 . 8}$ & $\mathbf{2 3 . 3}$ & $\mathbf{3 0 . 7}$ & $\mathbf{3 9 . 8}$ & $\mathbf{1 5 . 6}$ & $\mathbf{2 5 . 2}$ \\
M S health measures & $\mathbf{4 0 . 0}$ & $\mathbf{5 0 . 0}$ & $\mathbf{5 5 . 0}$ & $\mathbf{5 1 . 5}$ & $\mathbf{2 2 . 6}$ & $\mathbf{2 1 . 6}$ & $\mathbf{3 8 . 5}$ & $\mathbf{1 0 0}$ \\
Compliance/competence & $\mathbf{2 9 . 2}$ & $\mathbf{4 7 . 9}$ & $\mathbf{3 . 5}$ & $\mathbf{1 1 . 5}$ & $\mathbf{5 9 . 6}$ & $\mathbf{2 9 . 3}$ & $\mathbf{5 6 . 9}$ & $\mathbf{2 9 . 6}$ \\
A bsence or staff health & 0.0 & $\mathbf{1 0 . 7}$ & $\mathbf{9 5 . 9}$ & $\mathbf{6 4 . 6}$ & $\mathbf{7 1 . 2}$ & 0.0 & $\mathbf{1 0 0}$ & $\mathbf{9 9 . 5}$ \\
Quality of care & $\mathbf{7 5 . 0}$ & $\mathbf{8 0 . 0}$ & 100 & $\mathbf{6 9 . 0}$ & $\mathbf{6 4 . 2}$ & $\mathbf{8 6 . 7}$ & $\mathbf{8 8 . 8}$ & $\mathbf{7 9 . 5}$ \\
Incidents and accidents & 0.0 & $\mathbf{9 7 . 3}$ & $\mathbf{8 9 . 5}$ & $\mathbf{6 9 . 8}$ & $\mathbf{8 2 . 5}$ & $\mathbf{7 2 . 0}$ & $\mathbf{8 9 . 8}$ & $\mathbf{8 8 . 5}$ \\
Psychology well-being & $\mathbf{7 6 . 2}$ & $\mathbf{8 2 . 4}$ & $\mathbf{7 7 . 7}$ & $\mathbf{7 0 . 7}$ & $\mathbf{7 5 . 0}$ & $\mathbf{7 0 . 3}$ & $\mathbf{7 1 . 7}$ & $\mathbf{8 1 . 2}$ \\
Patient condition & $\mathbf{6 4 . 5}$ & $\mathbf{7 9 . 9}$ & $\mathbf{4 5 . 0}$ & $\mathbf{6 5 . 9}$ & $\mathbf{6 4 . 2}$ & $\mathbf{6 2 . 5}$ & $\mathbf{6 9 . 1}$ & $\mathbf{8 4 . 4}$ \\
Patient perception & $\mathbf{6 8 . 7}$ & 100 & 100 & $\mathbf{6 6 . 7}$ & 100 & $\mathbf{5 2 . 1}$ & $\mathbf{9 3 . 3}$ & $\mathbf{9 0 . 0}$ \\
M S exposure measures & $\mathbf{6 4 . 0}$ & $\mathbf{7 0 . 8}$ & $\mathbf{5 2 . 1}$ & $\mathbf{5 5 . 2}$ & $\mathbf{7 9 . 4}$ & $\mathbf{7 5 . 8}$ & $\mathbf{7 1 . 6}$ & $\mathbf{9 7 . 1}$ \\
Patient injury & 0.0 & 0.0 & $\mathbf{9 1 . 8}$ & $\mathbf{6 6 . 8}$ & $\mathbf{1 0 0}$ & $\mathbf{1 0 0}$ & $\mathbf{1 0 0}$ & $\mathbf{1 0 0}$ \\
Financial & 100 & 100 & 100 & 100 & 100 & 100 & 100 & 100 \\
\hline \multicolumn{1}{c}{ IET SC ORE } & $\mathbf{3 8 . 5}$ & $\mathbf{5 3 . 0}$ & $\mathbf{5 3 . 2}$ & $\mathbf{4 6 . 0}$ & $\mathbf{5 3 . 5}$ & $\mathbf{4 2 . 3}$ & $\mathbf{5 8 . 4}$ & $\mathbf{6 5 . 6}$ \\
\hline
\end{tabular}

\section{DISCUSSION}

This study has reviewed a wide variety of data from literature and empirical sources. The process of measuring and comparing different types of patient handling interventions has been addressed with the development of the Intervention Evaluation Tool. Every effort has been made to draw the content from studies and measurement methods that have either a good academic score or have proven validation. Some outcome areas were poorly represented in patient handling studies, in particular those relating to patient conditions and quality of care. The IET has undergone several peer review evaluations and has been translated into a further $3 \mathrm{EU}$ languages to allow for further evaluation.

The IET is created to collect a comprehensive set of data from a ward or unit and calculate 12 individual section scores and an overall score to show the effectiveness of the management processes for patient handling. It can be used as a before and after intervention comparison or to compare different types of interventions in similar settings. The IET has been developed to include two distinct forms. Firstly there is a guidebook for managers which outlines the structure of the IET and clearly shows the calculation and scoring process. Secondly there is a data collection format and a series of data collection forms to aid the process. The data collection consists of only 4 sections; a management survey for workload and staff structure, a safety culture audit, transfer observations for 
$25 \%$ of patients, and a questionnaire survey for $50 \%$ of staff and $25 \%$ of patients. The calculation of the IET scores for the separate and combined scores has been devel oped into an excel spreadsheet.

The detailed investigation of the different intervention studies and the focus groups has developed a clearer picture of the outcomes that are valued among the patient handling specialists in healthcare. There has been a move towards a more organisational and behavioural focus. The measures of safety culture and competence/compliance have featured highly alongside the traditionally high ranking M SD and sickness absence. This shift of perspective may suggest that most patient handling specialists consider the physical risks are manageable with the equipment/engineering solutions that are available in the marketplace and that the future developments are to be focussed on delivering a more compliant organisation.

The IET scores in Table 5 show differentiation between the wards. A simple 113 score was been assigned to the 12 sections (IET total, 87). The weightings and calculation structure will need to be part of any future evaluation and validation. The initial results are encouraging and allow for differentiation between different management systems. If a local facilitator can distribute the staff survey and prepare the access for the transfer observations, the time on the ward is approximately 3 hours. Complications of missing data and lack of observation do increase data collection time.

M uch work needs to be completed to develop and validate this proposed tool. If the IET proves to be a usable and efficient measurement tool then it will be possible to identify the strengths and weaknesses in an organisation from the individual rating scores in the 12 sections and an overall performance score for patient handling interventions. This will allow future interventions to be designed with specific outcomes and gains for the participating organisation, giving the opportunity for more directed interventions to enable best return on financial investment.

\section{REFERENCES}

A mick B., Tullar J., Brweer S., Irvine E., M ahood Q., Pompeii L., Wang A., V an E erd D., Gimeno D., Evanoff B. (2006). Interventions in heal th-care settings to protect muscul oskel etal heal th: a systematic review. T oronto: Institute for W ork and Health, 2006

Bos E.H., Krol B., Van Der Star A., Groothof J.W., (2006), The effect of occupational interventions on reduction of musculoskeletal symptoms in the nursing profession. Ergonomics 49, 7, 706-723.

Charney W., (1997). The lift team method for reducing back injuries. AAOHN. Vol. 45, No. 6, 300-304.

Chhokar R; Engst C; M iller A, Robinson D, Tate R, Y assi A , (2005). The three-year economic benefits of a ceiling lift intervention aimed to reduce healthcare worker injuries. Applied ergonomics. $2005 \mathrm{M}$ ar; 36(2): 223-9.

Dickinson C. et al, (1992). Questionnaire development: an examination of the Nordic M usculoskel etal Questionnaire. Appl Ergon. V ol 23 No 3 J une 1992. 
Downs S.H. Black N. (1998). The feasibility of creating a checklist for the assessment of methodological quality of both randomised and non-randomised studies of healthcare interventions. J ournal of Epidemiological Community Health 52: 377-84.

Evanoff B., B ohr P., W olf L., (1999). Effects of a participatory ergonomics team among hospital orderlies. Am. J. Industrial M edicine 35:358-365.

Fray, M. Hignett, S, (2006) An Evaluation of Outcome Measures in Manual Handling Interventions in Healthcare. In Pikaar, R.N., Konigsveld, E.A.P., Settels, P.J.M. (Eds.) Proceedings of the XVth Triennial Congress of the International Ergonomics Association, M eeting Diversity in Ergonomics 11-14 July 2006, M aastricht, N etherlands.

Higgins, J.M. (1994) 101 Creative Problem Solving Techniques. Florida: New $\mathrm{M}$ anagement Publishing $\mathrm{Co}$.

Hignett S, (2003). Intervention strategies to reduce musculoskeletal injuries associated with handling patients: a systematic review. Occup Environ Med;60:e6.

Hignett S, Crumpton, E., A lexander, P., Ruszala, S., Fray, M., Fletcher, B (2003) Evidence based patient handling- Interventions, tasks and equipment. London R outl edge.

Hignett S. and Crumpton E. (2005). Devel opment of a patient handling assessment tool. Int. J TR A pril 2005, V ol 12, No 4 178-181.

Hignett, S., Fray, M., Rossi, M. A., Tamminen-Peter, L., Hermann, S., Lomi, C., Dockrell, S., Cotrim, T., Cantineau, J. B., Johnsson, C. (2007). Implementation of the Manual Handing Directive in the Healthcare Industry in the European Union for Patient Handling tasks. International Journal of Industrial Ergonomics 37, 415-423.

Johhnsson C., Kjellberg K., Kjellberg A., Lagerstrom M., (2004). A direct observation instrument for assessment of nurses' patient transfer technique (DIN O). Appl Ergon. 35 (2004) 591-601.

Kjellberg K., Lagerstrom M., Hagberg M., (2004). Patient safety and comfort during transfers in relation to nurses' work technique. J. of Adv. Nursing, 47(3), 251-259

K nibbe J., Friele R., (1999). The use of logs to assess exposure to manual handling of patients, illustrated in an intervention study in home care nursing. IJ IE, 24 (1999) 445-454.

Martimo K.P., Verbeek J., Karppinen J., Furlan A.D., Takala E.P., Kuijer P., Jauhianen M., Viikari-Juntura E. (2008). Effect of training and lifting equipment for preventing back pain in lifting and handling: systematic review. BM J doi: $10.1136 /$ bmj.39463.418380.BE

N el son A., Collins J., Siddarthan K., M atz M., Waters T., (2008). Link between safe patient handling and patient outcomes in long term care. Rehabilitation Nursing, Vol 33, No 1 J an 2008.

Robson L.S., Clarke J.A., Cullen K., Bielecky A., Severin C., Bigelow P.L., Irvin E., Culyer A., Mahood Q. (2007) The effectiveness of occupational safety management system interventions: A systematic review. Safety Science 45 (2007) 329-353. 